\title{
Metachromatic leukodystrophy
}

\author{
INSERM
}

\section{Source}

INSERM. (1999). Orphanet: an online rare disease and orphan drug data base.

Metachromatic leukodystrophy. ORPHA:512

Metachromatic leukodystrophy (MLD) is a rare lysosomal storage disorder characterized byintralysosomal accumulation of sulfatides in various tissues, leading to progressive deterioration of motor and neurocognitive function. 